\title{
Metrópole, moeda e mercados. A agenda urbana em tempos de reemergência das finanças globais
}

\author{
Metropolis, money and markets. The urban agenda \\ in times of reemergence of global capital
}

Jeroen Klink [1]

\section{Resumo}

0 presente artigo explora a complementaridade entre a economia política e os estudos sociais das finanças para compreender a variedade de mecanismos pelos quais o capital financeiro se articula com a (re)produção da metrópole, com ênfase no contexto brasileiro. Depois de introduzir alguns conceitos básicos dos estudos sociais das finanças e de qualificá-los à luz da abordagem ortodoxa das finanças corporativas, apresento dois exemplos - a securitização dos tributos e a precificação da água na Grande São Paulo - de como essa vertente pode contribuir para a análise do maior entrelaçamento entre "a finança" e a metrópole. Concluo com recomendações para uma agenda de pesquisa que articule a economia política com os estudos sociais das finanças urbanas.

Palavras-chave: estudos sociais das finanças; capital financeiro; economia política; governança metropolitana compartilhada; governança corporativa.

\begin{abstract}
This paper explores the complementarities between political economy approaches and social studies of finance to build an understanding of the varied mechanisms through which finance capital connects with the (re)production of the metropolis, emphasizing the Brazilian context. After introducing the basic concepts of the social studies of finance and qualifying them in light of the orthodox approach of corporate finance, I discuss two examples of the potential insights this approach provides for the analysis of the interaction between finance capital and the metropolis, one related to the securitization of taxes, the other associated with water pricing in Greater São Paulo. The paper is concluded with recommendations for a research agenda that connects political economy with social studies of urban finance.
\end{abstract}

Keywords: social studies of finance; finance capital; political economy; shared metropolitan governance; corporate governance. 


\section{Introdução}

Este artigo tem como objetivo principal explorar a articulação entre a teoria urbana e a economia política da urbanização, de um lado, e os estudos sociais de finanças, de outro. Como objetivo complementar, busca verificar o potencial dessa articulação para contribuir com uma agenda de pesquisa sobre os mecanismos socioeconômicos, políticos e ideológicos pelos quais o capital financeiro avança, no cenário contemporâneo, sobre a produção social do espaço nas metrópoles brasileiras.

É desnecessário enfatizar os avanços que ocorreram na teoria urbana, principalmente a partir dos anos 1970, no que se refere à construção de uma reflexão sobre o papel das cidades no processo de reestruturação produtiva. Vários autores de inspiração marxista buscaram complementar a abordagem do materialismo histórico - recortado para a análise do conflito capital-trabalho ao longo do tempo com uma leitura que também aprofundasse as dimensões espaciais da trajetória capitalista. Protagonistas, como Soja (2001): a geografia e a história da reestruturação das metrópoles norte-americanas, principalmente, em Los Angeles; Harvey (1982): leitura das dimensões espaciais na obra do Marx; Lefebvre (2001): direito à cidade e à tensão criativa entre 0 espaço abstrato do mercado e o espaço diferencial da vida quotidiana; e Castells (1977): dimensão ideológica da questão urbana, movimentos sociais e o consumo coletivo, entre os exemplos mais emblemáticos, colocaram a cidade no centro das atenções em suas pesquisas sobre as transformações multifacetadas em curso, em escala mundial. Outros trabalhos retomaram e atualizaram a investigação da economia política clássica sobre temas como a geração e a apropriação de valor em torno do ambiente construído, a renda da terra e o papel de agentes como o proprietário e a incorporadora (Ribeiro, 1991; Topalov, 1974; Abramo, 2009).

Essa literatura proporcionou chaves analíticas importantes para a economia política e para os estudos urbanos avançarem na leitura das crescentes contradições socioespaciais que se acumularam nas metrópoles do Estado de bem-estar social nos países centrais até 0 colapso do sistema de regulação internacional de Bretton Woods, no início dos anos 70 do século passado. ${ }^{1}$ Esses esforços teóricos também proporcionaram uma base para fazer leituras sobre o ponto de inflexão que ocorreu no período pós-Bretton Woods, em termos de reescalonamento e reestruturação do Estado, neoliberalização dos espaços urbanos via grandes projetos estratégicos e fragmentação e mercantilização das redes de infraestrutura, entre os temas mais importantes abordados. Essa agenda de pesquisa também avançou na leitura da neoliberalização com um processo não linear (com revezamento entre "rodadas" de recuo e ampliação do Estado), contestado e marcado pelo hibridismo em função da presença contraditória de projetos e estratégias estatais de desregulação e re-regulação (Brandão; Fernández; Ribeiro, 2018; Brenner, 2004; Graham; Marvin, 2001; Barcellos de Souza, 2013).

No entanto, a implosão do sistema Bretton Woods significou mais do que uma mera mudança nas regras internacionais do jogo monetário e foi acompanhada por transformações profundas que influenciaram tanto 
a economia quanto o modo de regulação em escala mundial. A troca para um sistema de câmbio flexível (transformando as moedas nacionais em objeto de especulação dos investidores nacionais e internacionais, apostando nas oscilações dos principais preços macroeconômicos, como o câmbio e a taxa de juros), a desregulação e a liberalização dos mercados financeiros nacionais, a criação de novas engenharias financeiras como os derivativos e mercados secundários (veja próxima seção) e, por último, mas não menos importante, a reemergência das finanças globais ${ }^{2}$ deixaram profundas marcas nas cidades. Marcas estas apenas parcialmente analisadas pela teoria urbana crítica que emergiu nos anos 1970.

As evidências das articulações entre 0 capital financeiro e o urbano proliferaram-se no cenário pós-Bretton Woods. As complementaridades entre o projeto neoliberal; as políticas de austeridade e o endividamento individual mediado pelo Estado (que reduziu os subsídios para o consumo coletivo e fomentou a "inclusão financeira") (Byrne, 2016; López e Rodríguez, 2011); ${ }^{3}$ a proliferação de estratégias heterodoxas adotadas pelos governos locais para acessar os mercados de capitais por exemplo, via a antecipação de recursos tributários (Weber, 2010) -; e, mais recentemente, a própria crise subprime (Aalbers, 2012) mostraram a diversidade de entrelaçamentos entre as cidades e o capital financeiro. 0 ambiente apenas reforçou, se isso ainda fosse necessário, a necessidade de complementar as perspectivas críticas com uma visão mais clara acerca das relações imbricadas entre a moeda, o crédito e as finanças, de um lado, e a dinâmica temporal-espacial das cidades no capitalismo contemporâneo, de outro.
Harvey (1982) foi inegavelmente um dos primeiros a avançar nessa direção quando explorou a tendência de a terra transformar-se em ativo financeiro. Todavia, ao mesmo tempo, deixou em aberto as condições específicas nas quais isso ocorreria, assim como os agentes que consolidariam referida mudança. Na realidade, preencher essas lacunas iria requerer uma compreensão mais detalhada sobre as mediações entre os mercados fundiário e financeiro. ${ }^{4}$

A emergência de uma literatura relativamente nova sobre o fenômeno de financeirização, em geral, e financeirização urbana, em particular, deve também ser vista nessa perspectiva (Klink e Denaldi, 2014; Klink e Barcellos de Souza, 2017; Zwan, 2014; Ribeiro e Diniz, 2017). Apontou que os entrelaçamentos do espaço, tempo e dinheiro/moeda não apenas tenderam a transformar a terra, mas também a própria condição urbana. Na visão de alguns dos autores que contribuíram para essa discussão, o avanço do capital financeiro sobre o urbano evidenciar-se-ia em processos de reestruturação das infraestruturas urbanas, dos recursos naturais e do próprio fundo público. Na era da capitalização "de quase tudo" (Lyshon e Thrift, 2007), a cidade teria se transformado em objeto privilegiado para gerar lucros financeiros.

No entanto, na visão de autores como Christophers (2015), a agenda de pesquisa sobre financeirização corre o risco de perder sua relevância política, considerando que ela prioriza a análise do que a finança faz (no sentido de "esticar seus tentáculos" na esfera da vida quotidiana dos outros, na maioria das vezes atores não financeiros), ao invés de investigar o que ela é (ibid.). Portanto, pesquisas 
posteriores sobre o tema deveriam fazer um esforço na direção de entender melhor o processo constituinte da financeirização, priorizando os entrelaçamentos da moeda, do crédito e das finanças na transformação do espaço, da economia e da sociedade. Isso requer aprofundar a análise de mercados, em geral, e os creditícios e financeiros, em particular.

Christophers (2014a), indiretamente, também ajuda a entender o avanço paradoxalmente tímido da economia política na leitura da dinâmica das metrópoles em tempos de dominância da finança global. Pois a análise dos processos de alocação e circulação do valor em mercados não tem sido objeto privilegiado da economia política clássica. Na visão desse autor, essa última vertente e o próprio Marx sempre priorizaram as questões relacionadas à geração e produção, em detrimento da circulação e distribuição do valor, processos estes que ocorrem nos mercados.

Na realidade, essa relutância da economia política clássica em dissecar conflitos distributivos em mercados não representa exatamente um fenômeno novo. Os debates entre Engels e os socialistas utópicos, quando o primeiro argumentava que o conflito entre inquilino e proprietário da terra no mercado fundiário a respeito do nível de aluguel, assim como o conflito entre o agiota e o tomador do empréstimo no mercado creditício, eram qualitativamente diferentes, para não dizer secundários, em comparação à disputa central que deveria nortear as análises críticas, isto é, a disputa entre o capitalista detentor dos meios de produção e o trabalhador em torno da produção da mais-valia. Na visão do Engels, deslocar o recorte da análise para os conflitos distributivos nos mercados capitalistas seria confundir causas e consequências, pecado central do projeto político e intelectual dos socialistas utópicos como Proudhon (Engels, s/d).

Neste artigo, argumentamos que analisar a construção social dos mercados, em geral, e dos mercados creditício e financeiro, em particular, proporciona chaves analíticas importantes para articular a dimensão tanto da produção quanto da circulação e distribuição do valor nas metrópoles na fase atual do capitalismo. Mais particularmente, exploramos a potencialidade de uma literatura específica para desempenhar esse papel de coadjuvante para enriquecer a economia política da urbanização. Referimo-nos a uma discussão que se originou na literatura sobre ciência e tecnologia e na sociologia de ciências. Autores como Callon (1998) e Mackenzie (2005) elaboraram uma conceituação dos mercados, em geral, e dos mercados financeiros, em particular, como "um conjunto de agenciamentos sociotécnicos, que podem ser considerados como uma combinação de dispositivos materiais e técnicos, textos, algoritmos, regras e pessoas que moldam agenciamento e dão sentido à ação" (Berndt e Boecker, 2009, p. 543)..$^{5}$ Referidas discussões culminaram na consolidação de uma literatura específica sobre o tema da performatividade da ciência econômica. 0 conceito dialoga com a ideia de que a ciência econômica não apenas descreve a realidade; também seus conceitos, métricas, dispositivos e modelagens são ativamente utilizados pelos agentes públicos e privados na constituição social dos mercados. Berndt e Boeckler (2009, p. 544), com base do Callon, argumentam que

não são tanto os economistas acadêmicos [chamados por Callon como "os economistas enjaulados"] que fazem com que 
"o modelo do mundo vira o mundo do modelo", mas antes os profissionais das disciplinas sociotécnicas, como a contabilidade, a gestão das cadeias de valor ou a consultoria (os chamados economistas "soltos na natureza"), que estruturam e formatam os mercados, definindo padrões, sistematizando processos de troca, padronizando mercadorias, calculando preços, etc. $^{6}$

Argumentaremos que o conceito de performatividade da economia é relevante para compreender a constituição dos mercados creditícios e financeiros, assim como o seu entrelaçamento com a dinâmica das metrópoles. Mais especificamente, a utilização de determinados dispositivos, modelos e técnicas das ciências econômicas, pelos agentes sociais, na elaboração de estratégias de financiamento e de práticas de precificação e valoração, dentre os exemplos que serão discutidos, pode contribuir para gerar novo conhecimento sobre os mecanismos sociais, políticos e econômicos pelos quais o capital financeiro se articula com a (re) produção da metrópole. $^{7}$

Após esta introdução, o artigo estrutura-se em três seções complementares. Na primeira, discutimos os estudos sociais das finanças e suas possíveis contribuições para a economia política da urbanização. Nessa seção, apresentamos também conceitos básicos e métricas da economia financeira, assim como sua relevância para a economia política a partir da mediação dos estudos sociais das finanças e da ideia da performatividade. Na segunda, discutimos dois exemplos desse potencial de articulação entre as literaturas, um relacionado com a transformação do fundo público e outro dialogando com as disputas financeiras que paulatinamente transformam o ambiente institucional do setor de saneamento ambiental na Região Metropolitana de São Paulo. Na terceira seção, retornamos ao campo da economia política da urbanização, com breves recomendações para a elaboração de uma agenda de pesquisa que articule as promessas epistemológicas dos estudos sociais das finanças com este arcabouço teórico, com ênfase em três questões entrelaçadas e relevantes para o cenário brasileiro contemporâneo, isto é, Estado, fundo público e austeridade; neoliberalização e transformação da governança metropolitana; e papel dos modelos e da modelagem no planejamento urbano-metropolitano.

\section{Uma introdução ao vocabulário dos estudos sociais das finanças urbanas}

Cabe, primeiramente, justificar a necessidade de explorar uma vertente teórica específica, isto é, os estudos sociais das finanças, para aproximar-se do tema da cidade e do capital financeiro. Em outras palavras, mesmo que a economia política não esteja colocando o tema dos mercados no centro de suas preocupações, poder-se-ia argumentar que a economia neoclássica mainstream já se encarrega de analisar - até de forma exaustiva - a alocação e distribuição do valor em mercados.

No entanto, a abordagem neoclássica paradoxalmente obscurece a visão mais clara sobre a construção social dos mercados. ${ }^{8}$ Em parte, isso também remete à desconfiança tradicional da economia política, mencionada anteriormente, em investigar as aparências que se revelam a partir dos preços. Pois, ao mesmo 
tempo que o mecanismo de preços, como uma verdadeira mão invisível, transmite as informações necessárias para os agentes individuais (isto é, os consumidores e produtores) racionalmente adequarem suas escolhas, a somatória desses comportamentos e escolhas individuais retroalimenta, no constructo metodológico neoclássico, uma demanda e uma oferta coletiva que geram novo preço de equilíbrio. Portanto, na economia neoclássica, o mecanismo descentralizado de preços representa o elo entre o individualismo metodológico e a eficiência coletiva, ou seja, entre as partes e a soma, sem que se avance na compreensão do mercado como construção social. ${ }^{9}$

0 ponto de partida dos estudos sociais das finanças recortados para a ideia da performatividade é que os modelos das ciências econômicas e da economia financeira não apenas passivamente descrevem o mundo, mas são ativamente utilizados pelos atores sociais - por meio de uma série de práticas, regras e normas, técnicas e modelagens - na construção dos mercados como um conjunto de dispositivos de cálculo e de agenciamentos coletivos (Callon, 1998). Nas palavras de Faulhaber e Baumol (1988), como a engenharia e a medicina, as métricas e técnicas inventadas pelos economistas contribuem para gerar inovações e transformar o mundo.

A ideia de performatividade foi inicialmente aplicada no campo das finanças corporativas, mais especificamente em relação à previsão do preço das ações na bolsa de valores. ${ }^{10}$ MacKenzie (2005) foi um dos principais protagonistas dessa vertente a partir de seus trabalhos sobre o modelo de precificação do Black e Scholes (1972), amplamente utilizado no mercado futuro. Esse autor argumentou que, considerando que grande número de operadores estava utilizando o mesmo modelo, simulando-o com parâmetros que estavam convergindo no que se refere à evolução das principais variáveis econômicas em função da circulação de normas, convenções e informações entres eles, as práticas de comercialização dos produtos financeiros acabavam se comportando de acordo com as projeções do próprio modelo. Trabalhos semelhantes apontaram que os métodos e técnicas utilizados nos modelos de avaliação econômico-financeira não apenas mudaram as normas e convenções para o planejamento e coordenação da vida econômica, mas gradualmente penetraram também no desenho e na implementação de políticas culturais, sociais e ambientais. Chiapello (2015), por exemplo, discute como, no contexto europeu, as métricas para projetar a capacidade de gerar renda de determinados ativos no futuro, amplamente utilizadas pela economia financeira para a avaliação de projetos e programas, têm paulatinamente transformado as práticas tradicionais da contabilidade, que estavam estruturadas em torno do princípio de custos históricos, baseados no momento da aquisição dos bens e ativos no passado.

No que se refere ao objetivo mais específico deste artigo, cabe primeiramente definir melhor alguns conceitos básicos utilizados nos estudos sociais das finanças e qualificá-los, particularmente à luz da teoria de finanças corporativas que tende a esvaziar o conteúdo social das técnicas e métricas financeiras.

0 primeiro conceito básico é a constituição social de ativos, uma tradução livre do conceito assetization, utilizado por autores como Guironnet e Halbert (2015) e Birch (2017) quando analisam o processo de transformar 
objetos, como infraestrutura urbana, moradia e as várias dimensões que compõem a cidade e a própria vida, em ativos comercializáveis, que geram renda periódica (na linguagem de Guironnet e Halbert, os chamados tradeable income yielding assets). Diferentemente da categoria mercadoria (que também pode ser comprada e vendida), um ativo gera um direito para receber renda associada à propriedade, conforme evidenciada na propriedade intelectual (que gera patentes) e na propriedade da terra (que gera renda ou aluguel da terra), dentre alguns dos exemplos mais conhecidos.

A existência de ativos não pode ser naturalizada, como ocorre na nova economia institucional (Moulaert, 2005) ou na economia dos custos transacionais (Haila, 2016). Ativos emergem a partir de um processo social conflituoso, que envolve definir e recortar o escopo, assim como os parâmetros jurídicos e financeiros de propriedades, como a terra, a propriedade intelectual ou os recursos naturais e os de propriedade comum. Referidos parâmetros são ancorados nos conceitos da governança corporativa e na ideia de shareholder value (valor do acionista), que buscam enquadrar, para o detentor dos ativos, a redução de risco, a transparência e a confiabilidade das informações e a maximização dos ganhos associados à renda periódica e à valorização do investimento inicial (Froud, Sukhdev e Williams, 2002; Grün, 2007). Nesse sentido, a constituição de ativos também implica uma relação social e mercantil entre proprietário e usuário que compra o direito de usar determinada propriedade.

Por fim, o próprio processo de neoliberalização cria ambiente propício para crescente elasticidade e capacidade de estender a constituição social de ativos para a esfera dos bens e dos recursos de propriedade comum (os chamados comuns) (Bakker, 2007). Exemplo emblemático dessa tendência ocorre em casos como a criação de direitos comerciáveis para usar a água, evidenciado em países como o Chile (Solanes, 2013).

Um segundo conceito básico refere-se à técnica de capitalização, que significa antecipar, ou trazer para o presente, um fluxo de renda a ser recebido durante certo período no futuro. A transformação de um fluxo futuro de renda para o presente requer descontá-lo com a taxa de juros esperada durante o período considerado. Autores ortodoxos, como Faulhaber e Baumol (1988) e o próprio Harvey (1982), observam que o processo de capitalização não é novo. Por exemplo, os comerciantes italianos e belgas/holandeses já utilizaram a técnica, por meio da emissão de letras comercias que eram depositadas e descontadas nos bancos, com o intuito de antecipar seus recebíveis que se originaram no comércio internacional entre as cidades renascentistas. No entanto, o crescimento exponencial do mercado secundário e dos processos de securitização (nos quais se comercializam uma variedade de certificados de recebíveis e ativos) no período pós-Bretton Woods transformou a técnica de capitalização em um instrumento essencial nas finanças corporativas modernas.

Um terceiro conceito básico é a precificação, que se refere ao processo no qual a técnica de capitalização se entrelaça com a circulação de normas, regras e convenções, dentro de uma comunidade profissional, e com a construção coletiva do mercado como um conjunto de dispositivos de cálculo e de agenciamentos. Cabe ressaltar que a precificação está intrinsecamente relacionada com a prática social 
de quantificação em geral (Desrosières, 2002). No caso específico da precificação de ativos e propriedades, trata-se de transformar um fluxo de renda a ser recebido no futuro em estoque de valor no presente, processo este que é mais aberto e indefinido que o sugerido pela economia financeira ortodoxa. Mais particularmente, não há nada inerente à prática social de precificação e capitalização que não gere, conforme argumenta a economia mainstream, um preço de equilíbrio que reflita o valor real das mercadorias e o valor financeiro dos ativos com base nas expectativas racionais dos investidores. ${ }^{11}$ Na perspectiva dos estudos sociais das finanças ou da economia convencional (Sanfelici e Halbert, 2015), os preços emergem a partir da circulação de normas, regras, convenções e expectativas, que são pactuadas no âmbito de determinada comunidade profissional. Referida pactuação é estruturada em torno de variáveis-chave, como a percepção do risco, a projeção da renda futura periódica e a taxa de retorno a serem utilizadas nos cálculos econômicos.

Nitzan e Bichler (2009) levam esse raciocínio acerca do caráter social da capitalização e precificação a uma direção que se aproxima da economia política. Mais particularmente, lançam mão do conceito de capitalização diferencial como poder, isto é, um processo marcado pelas relações sociais desiguais entre agentes sociais, que se reflete na capacidade diferenciada para influenciar a circulação de informações e formação de expectativas (às vezes exageradas, que eles chamam de hipe) acerca de preços de ativos e empresas.

Um último conceito básico que precisa ser explicitado diz respeito ao lucro financeiro associado à compra e venda de ativos em mercados (secundários) por agentes que buscam maximizar o ganho de capital (isto é, a diferença entre o preço de venda e o investimento inicial), reduzir riscos ou obter liquidez. Pois, qualquer ativo financeiro não apenas gera uma renda periódica (ancorada no contrato inicial que estabelece os parâmetros jurídicos e financeiros da remuneração), mas também proporciona possíveis ganhos de capital - isto é, a diferença entre o preço de compra e de venda do ativo (Lapavitsas, 2013) -, opções para criar liquidez a partir de fixidez (Gotham, 2009) e proteção contra riscos e flutuações nos preços macroeconômicos (como juros e câmbio), por meio de operações de compra e venda no mercado futuro. ${ }^{12}$

Os conceitos básicos sintetizados acima não podem ser dissociados do papel central do Estado, em geral, e do planejamento urbano e regional, em particular, na construção social de novos mercados creditícios e financeiros, especialmente quando estes últimos ainda não estão consolidados. Conforme discutiremos na próxima seção, as técnicas, métricas e modelagens da economia não apenas circulam no âmbito "do mercado" stricto sensu, mas crescentemente envolvem e mobilizam os profissionais responsáveis pelo planejamento, gestão e financiamento dos territórios metropolitanos. Sem ter a pretensão de esgotar esse debate, discutimos brevemente, na próxima seção, a construção e disseminação de novos mecanismos de financiamento para as cidades, via a securitização do fundo público e os dispositivos financeiros utilizados para valorar e precificar as infraestruturas urbanas. 


\section{As finanças "em ação" nas metrópoles brasileiras}

Nas notas que se seguem, analisamos alguns dos mecanismos utilizados recentemente na constituição de novos mercados creditícios e financeiros nas cidades brasileiras. Apresentamos dois exemplos, um baseado na proliferação de estratégias heterodoxas utilizadas por municípios e estados para acessar o mercado de capitais, o outro recortado para um estudo de caso mais específico sobre as disputas financeiras e institucionais em torno da precificação da água na Região Metropolitana de São Paulo (RMSP). Os dois exemplos mostram variações do mesmo tema, isto é, de que modo a utilização de métricas, técnicas e modelos de precificação de ativos, de governança (corporativa) e de gestão de risco começa a gerar um ambiente de performatividade da economia na construção social de novos mercados creditícios e financeiros nas metrópoles brasileiras. Os exemplos também apontam o crescente entrelaçamento entre o capital financeiro e o urbano em áreas além do circuito imobiliário, tema já discutido com maior frequência na literatura brasileira (Royer, 2014; Fix, 2011; Shimbo, 2012).

\section{Financiamento, fundo público e mercado de capitais ${ }^{13}$}

Diferentemente do ambiente institucional norte-americano (Weber, 2010; Peck e Whiteside, 2016), as cidades brasileiras não têm acesso direto ao mercado de capitais, e os limites para a capacidade de endividamento são regulamentados pela Lei de Responsabilidade Fiscal (lei complementar n. 101, de 4 de maio de 2000) e por diversas resoluções do Conselho Monetário Nacional e do Senado.

No entanto, recentes e polêmicas experiências em curso nos diversos municípios e estados federados sugerem que haja uma pressão para a constituição de novos mecanismos de financiamento para o setor público que 0 articulem diretamente com os mercados de capitais. Mais especificamente, a emergência de uma "nova safra" de empresas estatais, como a Companhia Paulista de Securitização, a PBH-Ativos S/A, no município de Belo Horizonte, a Companhia Paranaense de Securitização, a InvestPOA S/A e a Companhia de Desenvolvimento e Mobilização de Ativos de Salvador, dentre os exemplos mais emblemáticos, aponta o surgimento de um modelo, que, inclusive, é objeto de circulação dentro de uma comunidade profissional de gestores públicos e privados. ${ }^{14}$ Quais são os principais dispositivos mobilizados pela nova prática institucional-financeira que norteiam a constituição dessas empresas e seus vínculos com o mercado de capitais (Canettieri, 2017)?

Primeiramente, os objetivos formais das empresas constituídas como a PBH-Ativos S/A é "administrar e explorar economicamente ativos", "auxiliar o tesouro na captação de recursos financeiros", "estruturar e implementar operações que visem à obtenção de recursos junto ao mercado de capitais" e objetivos específicos correlatos. ${ }^{15}$ Os objetivos mencionados não podem ser dissociados do quadro mais amplo, marcado pela austeridade fiscal e pela busca de novos recursos. Ao mesmo tempo, percebe-se uma tendência de acordo com a qual os entes federados lançam mão de um 
dispositivo jurídico - isto é, a criação de empresas estatais supostamente independentes, mas, na prática, sob controle acionário do município ou estado - com o objetivo de driblar os limites referentes à capacidade de endividamento público em vigor no país. Por exemplo, a emissão de títulos de dívida, lastreados a garantias públicas, é vedada pela Lei de Responsabilidade Fiscal. No entanto, as empresas estatais de securitização que foram criadas nos últimos anos desempenham o papel de pivô na montagem de novas engenharias financeiras e institucionais que buscam utilizar o fundo público e outros ativos estatais-urbanos como garantia para acessar o mercado privado de debêntures. ${ }^{16} \mathrm{Na}$ prática, o setor público lança mão do instrumento de cessão de ativos, como terrenos e imóveis públicos, empresas estatais de infraestrutura e de saneamento básico (veja a próxima seção) e o próprio fundo público - via créditos tributários e não tributários - com o objetivo de capitalizar a empresa estatal de securitização, para que esta última possa acessar o mercado privado de debêntures. No que se refere aos créditos tributários, estes são repassados pelo ente federado para a empresa pública de securitização em troca de debêntures subordinadas, que apenas pagam correção monetária e não são comercializáveis. Ao mesmo tempo, a empresa pública emite outro tipo de debênture simples, especificamente direcionada ao mercado de capitais, com garantias lastreadas aos direitos creditórios autônomos cedidos pelo ente federado. Estas últimas debêntures pagam juros de mercado e multa em caso de mora, cujos valores são corrigidos mensalmente de acordo com as cláusulas do contrato. ${ }^{17}$
Em segundo lugar, a constituição das empresas estatais camufla a assimetria na gestão de risco associada ao formato específico utilizado na emissão dos diversos tipos de debêntures. De um lado, o ente federado cedendo recursos tributários por meio da emissão de debêntures subordinadas pela empresa estatal de securitização (sem pagamento de juros), mantendo sua responsabilidade operacional pela cobrança dos tributos e disponibilização das informações aos investidores, de acordo com as premissas da transparência e da governança corporativa. De outro, a emissão de debêntures com garantia pública é cercada por uma série de mecanismos e métricas de monitoramento que busquem reduzir os riscos para os investidores privados e repassá-los, em última instância, para o ente federado. Por exemplo, uma conta separada centraliza os recursos tributários, incluindo os juros e as multas por mora dos contribuintes inadimplentes, como garantia para os investidores privados. Na experiência da empresa PBH-Ativos em Belo Horizonte, o contrato também previu um índice de garantia real de $200 \%$, implicando a necessidade de garantir nessa conta específica, mês a mês, um saldo devedor de créditos tributários vencidos duas vezes maior que o valor nominal atualizado não amortizado das debêntures em circulação (acrescido dos juros e demais encargos). Ainda no caso da cidade de Belo Horizonte, os planos de anistia fiscal, implicando descontos para pagamento à vista por contribuintes inadimplentes, automaticamente geraram obrigações para o município recompor o fluxo de caixa pactuado no momento da emissão das debêntures. 
Em terceiro lugar, o arranjo de empresas estatais "não dependentes", que lançaram mão de ofertas restritas de debêntures simples, isto é, envolvendo esforços limitados de colocação desses títulos, constituiu um ambiente institucional propício à criação de mercados secundários de debêntures que se situam à margem do sistema de fiscalização e supervisão do Banco Central, do Conselho Monetário Nacional e do Senado. Em várias ocasiões, a Comissão de Valores Mobiliários (CVM) deu anuência a ofertas restritas desses títulos com dispensa de pedido prévio de registro de oferta na bolsa de valores e de consulta junto ao Banco Central para que este se pronunciasse quanto a normas e resoluções sobre o endividamento público. ${ }^{18}$ Referida flexibilização pela CVM foi incentivada pelas instruções normativas anteriores, ${ }^{19}$ que instituíram um regime simplificado de oferta, permitindo, após um bloqueio inicial de 90 dias, a aquisição por até 50 investidores qualificados (implicando ticket mínimo de $\mathrm{R} \$ 1$ milhão, de acordo com as regras da bolsa de valores) e 75 investidores potenciais que poderiam ser consultados durante o processo de prospecção da oferta. Na prática, esse ambiente desencadeou um circuito paralelo oligopolizado, com poucos players bem-informados, estruturado em torno de criação e apropriação do lucro financeiro ou, na linguagem do Lapavitsas (2013) e Hilferding, "lucro de fundador" (veja também nota 12), associado a emissão e circulação das debêntures no mercado secundário. Nesse sentido, as "regras do jogo" para a precificação inicial de títulos com o perfil da $\mathrm{PBH}$-Ativos $\mathrm{S} / \mathrm{A}$, que não são negociados no mercado aberto, remetem às normas e práticas pouco transparentes em vigor na própria bolsa de valores para esse tipo de produto.
Por exemplo, da escritura da primeira emissão de debêntures com garantia pela PBH-Ativos S/A em Belo Horizonte, registrada na Junta Comercial do estado de Minas Gerais, consta que a precificação do título segue os procedimentos de bookbuilding, de acordo com o qual o banco coordenador da oferta avalia, a partir de um processo iterativo junto ao grupo seleto de investidores interessados e qualificados, a potencial demanda e o preço do lançamento. ${ }^{20}$

Por fim, ao mesmo tempo que surgiram polêmicas e investigações parlamentares em função do caráter pouco transparente do modelo que se disseminou em vários municípios e estados, presenciou-se um movimento político buscando proporcionar base jurídica mais sólida para a securitização de debêntures lastreadas em garantias públicas. Essa movimentação culminou no encaminhamento de Projetos de Lei do Senado (PLS n. 204, de 2016) e congresso (PL n. 3.337, de 2015) em torno da regulamentação da securitização da dívida ativa (CNACD, s/d).

\section{Débito-crédito, preços e o esvaziamento da governança compartilhada da água ${ }^{21}$}

Há algum tempo o tema da titularidade do saneamento básico nas regiões metropolitanas brasileiras tem sido objeto de disputas entre municípios e estados federados (Aversa, 2016). Apesar de o acórdão sobre a Ação Direta de Inconstitucionalidade (ADI n. 1.842), referente à titularidade de saneamento básico no estado do Rio de Janeiro, ter julgado pela responsabilidade compartilhada entre municípios e estados federados nas regiões metropolitanas, 
o cenário atual ainda deixou várias lacunas e incertezas quanto ao desenho específico do arcabouço institucional e financeiro que emergirá nos próximos anos.

Ao mesmo tempo, há indícios de que o próprio desenho da governança territorial compartilhada-participativa, vislumbrado principalmente pela legislação nacional do saneamento ambiental (lei n. 11.445, de 5 de janeiro de 2007) e pelo referido acórdão sobre a ADI n. 1.842, julgado pelo Supremo Tribunal Federal, sofreu um processo de esvaziamento em função do agravamento de disputas institucionais e financeiras, principalmente entre autarquias municipais e empresas estaduais. Tais disputas estão paulatinamente sendo estruturadas em torno de métricas, dispositivos e modelos emprestados da própria economia financeira e da literatura sobre a governança corporativa.

Nesse sentido, a precificação da água é tema central porque, do ponto de vista do capital financeiro, a receita tarifaria representa um fluxo de caixa estável e previsível que pode ser capitalizado e, portanto, reflete-se diretamente no preço das ações e no lucro financeiro do acionista. No entanto, existem outras pressões sociais em torno da precificação da água. Por exemplo, a política tarifária não pode ser dissociada das questões relacionadas com a arrecadação de recursos e do fundo público. Isso porque o preço da água está imbricada com o próprio arranjo do federalismo fiscal e, consequentemente, enraizado em projetos materiais e discursivos de neoliberalização, de austeridade fiscal e da necessidade de recuperação dos custos (marginais) (Swyngedouw, 2013). Por fim, o debate sobre a política tarifaria dialoga com a agenda estruturada em torno do direto à cidade e à água, conforme promulgado pelas agências multilaterais, na linha da Declaração de Dublin (Bakker, 2007).

Vejamos o caso emblemático da entrada de métricas e dispositivos financeiros e a transformação do modelo de governança na disputa entre a Sabesp, uma sociedade anônima, com ações registradas na Bolsa de Valores de São Paulo e Nova York, e o Serviço Municipal de Água e Saneamento Ambiental (Semasa), uma autarquia municipal responsável pelo saneamento ambiental (água, esgotamento, drenagem e resíduos sólidos) na cidade de Santo André, na Região Metropolitana de São Paulo (Klink, 2018).

Em novembro 2015, o Semasa encaminhou, junto ao Cade (Conselho Administrativo de Defesa Econômica), um requerimento para investigação da Sabesp. 0 Semasa argumentou que, desde meados dos anos 1990, a Sabesp utilizou sua posição de "quase-monopolista" no mercado de atacado para água no sentido de suprimir as margens das autarquias municipais. Os sucessivos desentendimentos sobre o preço correto da água desencadearam uma escalada no estoque da dívida de vários municípios junto à Sabesp. Dívidas estas que, na maioria das vezes, acabaram sendo negociadas de forma extrajudicial, por meio de acordos envolvendo perdão em troca da transferência dos ativos municipais e da responsabilidade pela gestão (incluindo a arrecadação das tarifas) para a Sabesp, que, por sua vez, já conseguiu negociar acordos desse tipo e assumir a gestão dos ativos em várias cidades da RMSP, como Osasco (1999), São Bernardo do Campo (2003) e Diadema (2013). 0 Semasa seria a próxima empresa municipal em uma trajetória marcada por "ofertas de aquisição hostil" e pelo gradual esvaziamento da governança territorial 
compartilhada do saneamento em áreas metropolitanas, envolvendo empresas municipais, concessionária estadual e população.

0 Semasa também questionou a posição contraditória da Agência de Regulação para Saneamento e Energia do Estado de São Paulo (Arsesp), criada em 2007 para regulamentar e supervisionar empresas como Sabesp. Antes dessa data, a política tarifária da Sabesp e das autarquias municipais foi executada por meio de decretos, em um contexto marcado pelo vácuo regulatório. Apenas no ano 2014, a Arsesp publicou a primeira nota técnica para orientar o processo de revisão tarifária para o período 2014-2017. Antes disso, a Agência nunca se preocupou com a investigação das métricas e práticas que substanciaram o cálculo da tarifa, limitando-se meramente a aprovar reajustes anuais de acordo com a taxa de inflação, com base na tarifa estabelecida anteriormente. 0 Semasa também ressaltou que a dependência dos recursos financeiros e humanos repassados ("a conta-gotas") pelo governo estadual reforçou o quadro de fragilidade e falta de autonomia da agência reguladora.

A Sabesp replicou que o requerimento de investigação do Semasa representou mais uma manobra em uma longa trajetória marcada pela recusa da autarquia municipal em pagar os verdadeiros custos da água (Cade, 2018):22

recolhendo, com poucos esforços, os benefícios gerados pelos usuários adimplentes dos demais municípios metropolitanos e repassando o ônus associado ao crescimento exponencial da dívida, incluindo multas e juros, para as próximas gerações da cidade. Considerando que os tribunais agora iniciaram o processo de cobrança judicial da dívida, a estratégia criativa do Semasa representou uma cortina de fumaça no iminente último estágio do conflito, re-escalonando e redirecionando-o para a esfera de regulação e preservação das estruturas concorrenciais de mercado.

0 argumento principal da Sabesp foi que o dispositivo do tipo price cap (Mourão, 2017), adotado pela Arsesp para nortear a elaboração e aplicação da política tarifária da água, não proporcionou qualquer incentivo para as práticas de discriminação de preços em detrimento das autarquias municipais. De forma geral, um arranjo price cap estabelece critérios para o ajuste anual dos preços, levando em consideração itens como inflação, aumento de produtividade e redução de ineficiências. No caso específico da Sabesp, o dispositivo foi combinado com uma fórmula para a fixação do preço inicial - ou preço-base (P0) -, baseada em uma versão adaptada de uma métrica financeira tradicional, isto é, o custo médio incremental de longo prazo (average incremental cost - AIC). Referida métrica é disseminada nos principais livros-texto sobre avaliação econômico-financeira de projetos de infraestrutura e também amplamente utilizada nas principais operações de empréstimo para esse setor pelas agências internacionais como o Banco Mundial (Bahl e Linn, 1992). É calculada, para determinado horizonte de planejamento, como a projeção dos custos de investimento e operação e manutenção por metro cúbico de água, capitalizados com a taxa esperada de retorno, no mesmo período. A Agência reguladora adotou uma taxa de retorno esperada baseada no custo médio de captação no mercado de ações e de debêntures, que foi fixada em 8,06\%. Na visão da Sabesp, esse teto para a taxa de retorno transformou qualquer estratégia de discriminação de 
preços nos diversos segmentos de mercado em uma espécie de jogo de soma zero; pois, cobrar mais no atacado implicaria margens menores no varejo (e vice-versa) para, assim, permanecer dentro do limite estabelecido para a taxa de $8,06 \%$. $^{23}$

Em novembro de 2017, o Cade rejeitou e arquivou o requerimento de investigação da Sabesp. 0 órgão baseou sua decisão em três argumentos: $^{24}$ (1) a Sabesp não tinha uma posição de monopolista no mercado de varejo na cidade de Santo André; ao contrário, em cidades metropolitanas com autarquias municipais - como o caso de Santo André -, esse monopólio é, de fato, praticado localmente pelo Semasa; (2) o Cade acatou o ponto de vista da Sabesp de que o processo de elaboração, revisão e ajuste anual da tarifa tinha ocorrido de acordo com diretrizes criadas e monitoradas por uma agência reguladora independente. Concordou também que o dispositivo de price cap eliminou eventuais vantagens associadas a uma política tarifária, discriminando mercados a jusante e a montante; e (3) mesmo que o órgão tenha explicitado que seu papel não era entrar no mérito específico de questões financeiras de dois players atuando no mercado, o Cade avaliou que, mais do que uma preocupação com a infração da ordem econômica pela Sabesp, o requerimento de investigação foi motivado pela recusa de o Semasa em aumentar o preço de varejo da água. Aumento este que poderia ter evitado a escalada de seus níveis de endividamento junto à Sabesp (Cade, 2018): ${ }^{25}$

0 mercado de água é inelástico no downstream, do modo que haveria espaço para aumento de preços nesse segmento, especialmente considerando que cada governo municipal tem liberdade para definir sua tarifa não tendo que se submeter a um valor máximo estabelecido por uma agência reguladora, como é o caso da Sabesp no varejo. Assim, especialmente estando o monopolista no downstream, premido por dívidas, seu cálculo de precificação deve considerar o repasse ao consumidor final do preço dos insumos. Contrariamente, o que parece acontecer no presente caso é uma estratégia do Semasa de diminuir os custos da água que fornece pagando menos do que o devido à Sabesp, com o intuito de não aumentar o preço final para o consumidor do município de Santo André.

Não é escopo aqui analisar com mais detalhes o indeferimento do requerimento de investigação da Sabesp (Klink, 2018). No entanto, o parecer do Cade foi notável por várias razões. Em primeiro lugar, o monopólio absoluto do Semasa no mercado de varejo para água deve ser relativizado, considerando a efetiva ameaça de entrada da Sabesp a partir de uma eventual negociação bem-sucedida em torno do perdão da dívida em troca de transferência de ativos municipais e de responsabilidade pela gestão local de saneamento para o sistema estadual. Além disso, o Cade claramente superestimou o grau de independência da agência reguladora, que até os próprios mercados e agências de avaliação como Moody já tinham problematizado (Moody's, 2013). Ao mesmo tempo, subestimou o número de brechas no dispositivo de price cap utilizado para nortear a elaboração e revisão das tarifas, que poderiam ser exploradas por práticas criativas de cálculo, particularmente dentro de um cenário marcado por falta de acesso aos dados e sistemas de informação da Sabesp. Uma dessas práticas foi criticada pelo Semasa e ficou também sem resposta no 
próprio processo do Cade. Mais particularmente, o Semasa contestou o argumento de que, no formato atual, a fórmula price cap eliminou as vantagens para a discriminação de preços no atacado e varejo, pois a eventual eficiência do dispositivo baseou-se no limite para a taxa de retorno sobre os ativos (de 8,06\%). No entanto, um acréscimo nos investimentos e, subsequentemente, no estoque de ativos não descartaria maiores lucros, em valores absolutos, em mercados específicos, mantendo, assim, a taxa de retorno dentro do limite percentual estipulado pela Arsesp. Em outras palavras, o próprio formato do dispositivo price cap proporcionou incentivos para a Sabesp artificialmente incorporar ativos existentes na fórmula (assetization), a partir de investimentos efetuados e já amortizados no passado. Por fim, o Cade argumentou que o Semasa, operando como monopolista no mercado de varejo para água, marcado pela baixa elasticidade do preço da demanda, deveria ter explorado seu potencial para maximizar a receita tarifária, repassando, desse modo, a escalada de preços no atacado, cobrados pela Sabesp para o consumidor final. ${ }^{26}$ Apesar de extrapolar suas competências como agência de regulação e supervisão da ordem econômica e, baseando-se no senso comum - isto é, de uma forma ou outra, que uma dívida seja paga -, a avaliação do Cade desviou-se da questão central da necessidade de uma investigação mais detalhada das relações imbricadas entre a trajetória da governança, a precificação e o financiamento do saneamento ambiental em Santo André e outras cidades metropolitanas em situação semelhante. A recusa para destrinchar tais "conexões desarrumadas" entre a gradual acumulação de um estoque de dívida e práticas diferenciadas para precificar a água e gerar fluxos tarifários significou que o Cade não interpretou devidamente seu papel na preservação de um sistema compartilhado de planejamento, gestão e financiamento do saneamento em áreas metropolitanas.

Enquanto isso, as negociações entre 0 Semasa e a Sabesp sobre o encaminhamento de um acordo estruturado em torno do perdão de dívida em troca de transferência de ativos municipais e de responsabilidade pela gestão para o governo estadual não avançaram, apesar da pressão da Sabesp para equacionar o impasse.

A própria Sabesp, a partir da lei n. 16.525 , de 15 de setembro de 2017, aprovada em regime de urgência, em menos de dois meses, foi objeto de uma reengenharia institucional-financeira que envolveu a criação de uma nova sociedade controladora por ações (holding), com participação majoritária do governo estadual. A sociedade exerce 0 controle acionário da Sabesp e tem por objetivo, dentre outros, "deter a titularidade, administrar e explorar ativos de qualquer natureza, visando precipuamente à universalização e à eficiência dos serviços de saneamento básico no estado de São Paulo", além de "estruturar e implementar operações de captação de recursos para fortalecimento da capacidade de execução de estratégias e ações no setor de saneamento básico" (lei n. 16.525, art. $2^{\circ}$, inciso II). A Sabesp imediatamente envolveu a International Finance Company braço especializado do Banco Mundial para o setor privado - com o pedido para desenhar a estrutura de capitalização da nova holding, que, por sua vez, subcontratou - Banco Itaú. Até setembro de 2018, o governo não avançou na viabilização da 
sociedade controladora. Ao mesmo tempo, em 9 de março do mesmo ano, recebeu uma carta de um grupo de investidores com a proposta de aquisição de parte das ações de propriedade de governo, que serão ainda emitidas pela sociedade controladora. 0 fato gera dúvidas sobre a continuidade de um projeto financeiro-institucional ancorado na propriedade majoritária das ações ordinárias do governo estadual. A medida provisória n. 844 (2018), referente à modernização do Marco Legal de Saneamento (assinada no dia 6 de juIho de 2018), e as notícias mais recentes sobre 0 apetite do capital financeiro e das empresas transnacionais, como Coca-Cola e Pepsi, para os ativos do setor de saneamento ambiental no Brasil, em geral, e no estado de São Paulo, em particular, apontam uma pressão para acelerar a transformação da governança territorial compartilhada para premissas do shareholder value e governança corporativa (Brasil De Fato, 2018; Britto e Rezende, 2017).

\section{À guisa de conclusão: dos mercados para a economia política}

0 campo dos estudos sociais das finanças proporciona insights importantes na análise dos agenciamentos e dispositivos coletivos de cálculo que articulam métricas, modelos e representações da economia financeira com a efetiva penetração de novos mecanismos de crédito e financiamento nas metrópoles. No entanto, a abordagem dificilmente nos permite uma leitura mais completa de questões relacionadas com a produção de valor, as relações sociais e o papel da ideologia, privilegiadas no âmbito do campo da economia política.

Portanto, com base nos exemplos discutidos na seção anterior e da crescente literatura que busca articular as vertentes (Berndt e Boeckler, 2009; Christophers, 2014b; Jessop, 2000; Klink e Barcellos de Souza, 2017), sugerimos, à guisa de conclusão deste artigo, ao menos três eixos temáticos (financiamento, fundo público e austeridade; neoliberalização e restruturação da governança metropolitana; e o papel da modelagem no planejamento urbano-metropolitano) para uma agenda de pesquisa marcada pela complementaridade entre a economia política de urbanização e os estudos sociais das finanças.

\section{Estado, fundo público e financiamento em tempo de austeridade metropolitana}

Vários autores mostraram o potencial do arcabouço relacional-escalar para analisar a variedade de estratégias e projetos de neoliberalização dos espaços metropolitanos (Brandão; Fernández; Ribeiro, 2018; Brenner, Peck; Theodore, 2010). Essa literatura abre perspectivas promissoras para investigar os processos contraditórios de reestruturação e reescalonamento do Estado nacional-desenvolvimentista em regiões metropolitanas. No entanto, um tema menos explorado nessa abordagem é o avanço do capital financeiro sobre o fundo público, mediado pelo próprio Estado (Royer, 2014). Em um contexto institucional marcado pelo baixo grau de consolidação do mercado de capitais, como é o caso brasileiro, a questão assume relevância ainda maior. 
Uma das hipóteses - a ser verificada em pesquisas mais específicas - é a centralidade da escala metropolitana como arena privilegiada para o avanço do capital financeiro. Como se sabe, as regiões metropolitanas brasileiras são marcadas pela ausência de um padrão de financiamento que garanta um fluxo de recursos em um horizonte de longo prazo, previsível e com base transparente (Rezende, 2010). Em nenhum momento, o Estatuto da Metrópole, agora reeditado e esvaziado de suas premissas originais para orientar o planejamento e a gestão das áreas metropolitanas, sinalizou que iria avançar no tema de financiamento metropolitano. ${ }^{27} \mathrm{~A}$ lei apenas providencia referências gerais para a constituição de instrumentos como operações urbanas consorciadas interfederativas e parcerias público-privadas, ambas gerando janelas de oportunidade privilegiadas para a inserção de novos dispositivos, métricas e modelagens financeiros. Por fim, a nova fase de austeridade que se anunciou a partir dos protestos de junho 2013 colocou paradoxalmente - o Estado no centro da arena metropolitana para mediar as disputas sobre a alocação do fundo público entre trabalhadores, o capital portador de juros e o capital produtivo. A proliferação de evidências dessas disputas (por exemplo, em torno do Fundo de Investimento do Fundo de Garantia do Tempo de Serviço - FI-FGTS - e os recursos tributários do orçamento-geral) aponta a necessidade de articular algumas das chaves analíticas discutidas aqui - como a constituição social de ativos, a capitalização diferencial e sua relação com a precificação e o lucro financeiro - com a releitura de análises de autores como Francisco de Oliveira sobre a crise no "padrão de financiamento público do welfare state", que operou como "verdadeira 'revolução copernicana' nos fundamentos de categoria de valor como nervo central tanto da reprodução do capital quanto da força de trabalho" (Oliveira, 1998, p. 27). Releitura esta ainda mais urgente à luz do fato de que o padrão de financiamento nacional-desenvolvimentista das cidades brasileiras nunca se equiparou ao desenho do keynesianismo espacial nos países centrais.

\section{Neoliberalização e reestruturação da governança metropolitana}

Outro eixo temático promissor de investigação emerge a partir da articulação entre a literatura sobre a neoliberalização urbana e as análises sobre o papel das finanças na reestruturação da governança territorial. Mais especificamente, a literatura sobre governança corporativa e os modelos de shareholder value apresenta uma relevância específica para o debate brasileiro sobre o planejamento e gestão das áreas metropolitanas, em geral, e das funções públicas de interesse comum, em particular (Bakker, 2007). Pois, no caso brasileiro, a investigação da penetração de novas racionalidades e métricas associadas ao conceito de shareholder value, como a constituição de ativos, assim como sua capitalização e precificação, requer mediações teóricas adicionais que mobilizem o próprio Estado nas múltiplas escalas. Isso se deve ao fato de que a disseminação de estratégias pautadas pela privatização em setores como saneamento ambiental, no contexto do esgotamento do nacional-desenvolvimentismo e do avanço do projeto neoliberal nos anos 1990, ainda foi relativamente modesta (Bayliss, 2014). Além disso, setores como saneamento 
ambiental ainda são marcados pela presença significativa de empresas estatais que foram criadas no auge da fase tecnoburocrática centralizada do nacional-desenvolvimentismo e continuam a desempenhar um papel estratégico no planejamento, gestão e financiamento dos sistemas metropolitanos.

Portanto, uma agenda de pesquisa sobre o planejamento e a gestão das redes de infraestrutura como saneamento ambiental, em tempos de reemergência das finanças globais, deve priorizar a tensão sistêmica entre as premissas da governança territorial compartilhada - mobilizando governos, movimentos sociais e sociedade civil organizada - e o avanço de uma lógica neoliberal específica, pautada pelas métricas, princípios e dispositivos do shareholder value dentro das próprias empresas estatais. Consequentemente - e diferentemente dos trabalhos referentes ao avanço direto dos agentes financeiros sobre o planejamento e a gestão das redes de infraestruturas em países centrais, com mercados de capitais consolidados (Pryke e Allen, 2017) - essa abordagem privilegia a análise das disputas institucionais e financeiras estruturadas em torno das empresas estatais. ${ }^{28}$ Isso evidentemente não exclui a análise detalhada dos bancos de investimentos e dos demais agentes financeiros, posto que estes estão presentes e procuram influenciar, com "suas" técnicas, métricas e modelos, os desdobramentos das disputas e do processo de reestruturação financeira e societária das empresas estatais na direção da maximização do lucro financeiro.
Planejamento urbano-metropolitano e ideologia 2.0: de planos para modelos

Conforme argumentamos anteriormente, as ideias da teoria de performatividade e dos estudos sociais das finanças são relevantes para entender que, sob determinadas circunstâncias, os "produtos" das ciências econômicas geram "inovações" que transbordam o próprio campo da economia e contribuem para a concreta transformação da vida quotidiana na metrópole. Nesse sentido, no próprio balanço da crise subprime nos EUA elaborado por Morris (2008), a modelagem matemática emerge como elemento importante na constituição e disseminação das novas engenharias financeiras que, ao mesmo tempo, dificultaram o controle e o monitoramento dos riscos sistêmicos nos mercados hipotecários globais.

Paralelamente, tais ideias precisam ser fundamentadas numa leitura da economia política sobre como os agenciamentos - que, além dos agentes financeiros tradicionais, mobilizam planejadores, consultores, atores do circuito imobiliário, entre outros exemplos - entrelaçam-se com a reestruturação da própria política urbana e do planejamento na metrópole.

Nesse sentido, a melhor compreensão de como esses agentes lançam mão de determinados modelos, métricas, técnicas e dispositivos financeiros para influenciar o desenho e a implementação de estratégias de precificação, valoração e financiamento da metrópole pode contribuir para atualizar a leitura do caráter iminentemente ideológico do planejamento urbano brasileiro (Villaça, 1999). 
De acordo com essa hipótese, os próprios modelos e métricas financeiras estariam complementando, e, talvez, paulatinamente substituindo, o papel ideológico dos planos; pois, os preços que emergem a partir das relações imbricadas entre determinadas práticas coletivas de calcular e usar dispositivos financeiros-institucionais tendem a naturalizar a assimetria de informações, os mecanismos contraditórios de compartilhamento de riscos entre o público e privado e as desigualdades sociais, além de produzirem um espaço pós-político que não revela as disputas sobre a produção e apropriação do valor na metrópole. De certa forma, a análise crítica das diversas etapas de "entrada da finança" na metrópole, que discutimos ao longo deste artigo, pode se beneficiar dos estudos sociais das finanças para desvendar a natureza real de tais disputas. Mais especificamente, a constituição de ativos, a apropriação desigual das métricas utilizadas na precificação e comercialização desses mesmos ativos pelos agentes sociais - a capitalização diferencial, na linguagem de Nitzan e Bichler (2009) - e, por último, mas não menos importante, o entrelaçamento desses processos com o próprio planejamento urbano-metropolitano representam arenas espaço-temporais privilegiadas para construir pontes com a teoria urbana crítica. Uma abordagem dessa natureza poderia também contribuir para lançar luz sobre os descompassos entre modelos e arranjos idealizados de parcerias público-privadas e de instrumentos urbanísticos orientados para 0 mercado, como a operação urbana consorciada via Certificados de Potencial Adicional de Construção (Cepac), de um lado, e a política urbana efetivamente existente a partir da utilização de determinadas práticas de cálculo, "emprestadas" e adaptadas dos manuais da economia financeira neoclássica, de outro (Klink e Stroher, 2017).

\section{[I] https://orcid.org/0000-0001-6264-001X}

Universidade Federal do ABC, Programa de Pós-Graduação em Planejamento e Gestão do Território. Santo André, SP/Brasil. jeroen.klink1963@gmail.com

\section{Notas}

(1) Cabe também ressaltar que uma literatura original explorou a espacialidade contraditória do modelo de urbanização e industrialização brasileira a partir de chaves analíticas, como espoliação urbana (Kowarick, 1979); relações imbricadas entre o atrasado e o moderno no Brasil urbano (Oliveira, 1972); e o urbano como espaço privilegiado da acumulação e da miséria (Maricato, 1987), entre os exemplos paradigmáticos. 
(2) Na expressão do Helleiner (1994), trata-se de uma "reemergência" das finanças globais, após a implosão do sistema Bretton Woods pelos estados nacionais, impulsionada por pressão do capital financeiro. O Bretton Woods (1945-1973) tinha imposto fortes restrições referentes à circulação internacional do capital financeiro e também consolidou um sistema de câmbio fixo, lastreando as moedas nacionais ao padrão dólar-ouro. Nesse sentido, o sistema rompeu com o período anterior, marcado pela efervescência do capital financeiro.

(3) Referidos autores argumentam que o keynesianismo espacial - caracterizado pela presença do Estado na subvenção direta do consumo coletivo das famílias via o fundo público - evoluiu para um keynesianismo de ativos, ou urbanismo de ativos, marcado pela delegação da responsabilidade pela provisão de moradia e serviços urbanos básicos para os mercados de crédito via estratégias de inclusão financeira.

(4) De certa forma, autores como Haila (2016) e Jäger (2003) procuraram avançar nessa direção.

(5) Tradução nossa do original: "Markets as sociotechnical agencements then have to be considered as a combination of material and technical devices, texts, algorithms, rules and human beings that shape agency and give meaning to action".

(6) Tradução nossa do original: "it is less that academic economists (termed 'confined economists') see to it that the 'model of the world becomes the world of the model' (Thrift, 2000, p. 694), but rather that the practitioners of sociotechnical economic disciplines such as accounting, supply chain management or consulting (termed 'economists in the wild'), frame and perform markets by defining standards, surveying exchange processes, benchmarking goods, calculating prices and so on".

(7) Cabe ressaltar, conforme também observa Christophers (2014a), que parte da literatura sobre a performatividade é objeto de críticas de autores que pertencem ao campo da economia política. Os principais pontos de divergência são a suposta ênfase no individualismo metodológico e a recusa dessa vertente para efetuar análises estruturais e de relações sociais. No entanto, de acordo com esse autor, a referida crítica desconsidera a variedade de abordagens na literatura sobre performatividade, inclusive as que permitem desenvolver um approach enraizado nas relações sociais e analisar as estratégias materiais e imateriais dos agentes sociais. Neste artigo, acompanho o método proposto por Christophers (2014a), estruturado em torno de idas e voltas "da economia política para o mercado" e "do mercado para a economia política". Para um argumento semelhante, veja também Henrikson (2009) e Berndt e Boeckler (2009).

(8) Na visão dos autores Berndt e Boeckler (2009, p. 542), para a vertente neoclássica, o mercado não é um problema; ele resolve problemas. Portanto, não requer ser transformado em objeto específico de investigação.

(9) Faulhaber e Baumol (1988) argumentam que mercados perfeitos e competitivos comportam-se de acordo com as descrições e os projeções das ciências econômicas neoclássicas. Nesse paradigma, qualquer análise ou descrição sobre como determinados agentes desenham e executam instrumentos e técnicas proporcionados pela ciência econômica (isto é, o objeto de análise dos estudos sociais de mercados) é redundante.

(10) Ver também Faulhaber e Baumol (1988) para uma visão da economia ortodoxa sobre a performatividade. 
(11) Na terminologia das finanças corporativas, o valor presente líquido representa a variável que sintetiza a mediação entre futuro e presente, por meio da capitalização, com a taxa de juros esperada. Isto é, o valor presente líquido é o valor do capital que tem de ser depositado hoje para beneficiar-se, como rentista, de determinado fluxo periódico de renda durante um horizonte temporal pactuado no futuro. Em mercados perfeitos e competitivos, o preço de equilíbrio dos ativos é equivalente ao valor presente líquido. Na visão de Lapavitsas (2011), o conceito valor presente líquido utilizado nas finanças corporativas corresponde ao capital fictício adotado por Marx.

(12) Na formulação do Hilferding, o "lucro do fundador" emerge a partir de uma oferta pública inicial de ações da empresa na bolsa de valores, em função da diferença entre o valor obtido na emissão e o investimento inicial (Lapavitsas, 2013, pp. 157-158).

(13) O material empírico desta seção é baseado na análise mais detalhada da experiência da empresa PBH Ativos S/A em Belo Horizonte, principalmente a partir da pesquisa documental dos contratos da empresa e da literatura consolidada sobre essa experiência (Canettieri, 2017). Os contratos estão disponíveis em: http://pbhativos.com.br/transparencia/contratos-e-convenios/. Acesso em: 10, 2 e 3 jun 2018.

(14) Não é objetivo deste artigo detalhar, para esses casos específicos, os mecanismos pelos quais ocorrem a circulação de modelos, políticas e "melhores práticas", também por meio de "agentes de transferência" (Baker e Temenos, 2015; McCann, 2011). De qualquer forma, para a experiência da PBH-Ativos S/A cabe destacar, por exemplo, o papel do sr. Edson Ronaldo Nascimento (ex-presidente), que também foi superintendente da fazenda de Goiás, secretário de Fazenda de Tocantins, consultor do Fundo Monetário Internacional (FMI), secretário de planejamento no Distrito Federal e ex-funcionário da Secretaria de Tesouro Nacional (CNACD, s/d; Canettieri, 2017).

(15) Citados no art. 20 da lei n. 10.003, de 25 de novembro de 2010, que criou a PBH Ativos S/A.

(16) Uma debênture é um título de dívida, comercializável no mercado secundário, que rende determinada taxa de juros fixada em contrato.

(17) A empresa PBH Ativos S/A pagou, em 2014, uma taxa de 11\% ao ano, mais a correção monetária, chegando a $23 \%$ (CNACD, s/d).

(18) Casos como a Companhia de Saneamento Básico de São Paulo (Sabesp), a Companhia Paulista de Securitização e a Companhia de Saneamento de Minas Gerais (Copasa - MG) (CNACD, s/d).

(19) Particularmente, a instrução normativa CVM/476-09, do ano de 2009.

(20) Mais especificamente, utilizando um intervalo inicial para os preços, o banco-líder (coordenador) verifica se a potencial demanda revelada pelos investidores atende a necessidade de financiamento. Se o interesse do mercado pelos títulos estiver menor que a necessidade de financiamento, significa que o preço inicialmente proposto se mostrou alto demais e sofrerá sucessivos ajustes até a demanda por títulos se aproximar da necessidade inicial de financiamento.

(21) As informações empíricas desta seção são baseadas em pesquisa documental do processo de requerimento de investigação do Serviço Municipal de Saneamento Ambiental de Santo André (Semasa) junto ao Conselho Administrativo de Defesa Econômica (Cade, 2018), assim como relatórios da Companhia de Saneamento Básico do Estado de São Paulo (Sabesp, 2016). Para mais detalhes, ver também Klink (2018). 
(22) Cade (2018), Arquivo: 167001/2012, p. 3.

(23) A fórmula utilizada no primeiro ciclo de revisão da tarifa (2014-2018) permitiu a incorporação de investimentos ainda não amortizados (isto é, investimentos efetuados no passado pela Sabesp). Isso representa uma diferença com o método tradicional de cálculo para o custo médio incremental de longo prazo, recortado para o futuro, de acordo com o qual apenas os investimentos e os custos de operação e manutenção novos são projetados e capitalizados para obter um preço de referência. Essa maneira de calcular aumentou a margem de manobra da Sabesp sobre a política tarifária, particularmente à luz da falta de acesso ao sistema de informações da empresa. Ver também: Bahl e Linn (1992) e Mourão (2017).

(24) Cade (2018); Nota técnica n. 13/2017/CGAA3/SGA1/Cade.

(25) Nota técnica n. 13/2017/CGAA3/SGA1/Cade, p. 12.

(26) Uma baixa elasticidade do preço da demanda quer dizer que a demanda está pouco sensível para flutuações no nível de preços. Nesse cenário, um aumento nos preços gera crescimento da receita tarifária.

(27) Trata-se da lei n. 13.683, de 19 de junho de 2018, que altera a lei n. 13.089, de 12 de janeiro de 2015 (Estatuto da Metrópole).

(28) Rooyen e Hall (2007) desenvolvem um raciocínio semelhante para o caso das empresas públicas de saneamento no cenário sul-africano.

\section{Referências}

AALBERS, M. B. (org.) (2012). Subprime cities: the political economy of mortgage markets. Oxford, Wiley Blackwell.

ABRAMO, P. (2009). Favela e mercado informal: a nova porta de entrada dos pobres nas cidades brasileiras. São Paulo, Antac.

AVERSA, M. (2016). História institucional do saneamento e da metropolização da grande São Paulo: trajetórias perdidas, conflitos inevitáveis. Dissertação de Mestrado. São Bernardo do Campo, Universidade Federal do ABC.

BAHL, R. W. e LINN, J. F. (1992). Urban Public Finance in developing countries. Washington, Oxford University Press.

BAKER, T. e TEMENOS, C. (2015). Urban policy mobilities research: introduction to a debate. International Journal of Urban and Regional Research, v. 39, n. 4, pp. 824-827.

BAKKER, K. (2007). The "Commons" versus the "commodity": alter-globalization, anti-privatization and the human right to water in the global South. Antipode, v. 39, n. 3, pp. 430-455.

BARCELLOS DE SOUZA, M. (2013). Variedades de capitalismo e reescalonamento espacial do Estado no Brasil. Tese de Doutorado. Campinas, Universidade Estadual de Campinas.

BAYLISS, K. (2014). The financialization of water. Review of Radical Political Economics, v. 46, n. 3, pp. 292-307. 
BERNDT, C. e BOECKLER, M. (2009). Geographies of circulation and exchange: construction of markets. Progress in Human Geography, v. 33, pp. 535-551.

$\mathrm{BIRCH}, \mathrm{K}$. (2017). Rethinking value in the bio-economy: finance, assetization, and the management of value. Science, Technology, \& Human Values, v. 42, n. 3, pp. 460-490.

BLACK, F. e SCHOLES, M. (1972). The valuation of option contracts and a test of market efficiency. Journal of Finance, v. 27, pp. 399-417.

BRANDÃO, C. A.; FERNÁNDEZ, V. R. e RIBEIRO, L. C. de Q. (2018). Escalas espaciais, reescalonamentos e estatalidades: lições e desafios para América Latina. Rio de Janeiro, Observatório das Metrópoles/ Letra Capital.

BRASIL DE FATO (2018). As águas do Brasil: o que vem por aí? São Paulo, Brasil de fato. Disponível em: https://www.brasildefato.com.br/2018/06/20/as-aguas-do-brasil-o-que-vem-por-ai/. Acesso em: 22 jun 2018.

BRENNER, N. (2004). New state spaces: urban governance and the rescaling of statehood. Oxford, Oxford University Press.

BRENNER, N.; PECK, J. e THEODORE, N. (2010). Variegated neoliberalization: geograhies, modalities, pathways. Global Networks, v. 10, n. 2, pp. 182-222.

BRITTO, A. L. e REZENDE, S. C. (2017). A política pública para os serviços urbanos de abastecimento de água e esgotamento sanitário no Brasil: financeirização, mercantilização e perspectivas de resistência. Cadernos Metrópole, v. 19, n. 39, pp. 557-581.

BYRNE, M. (2016). "Asset Price Urbanism" and financialization after the crisis: Irland's National Asset Management Agency. International Journal of Urban and Regional Research, v. 40, n. 1, pp. 31-45.

CADE - CONSELHO ADMINISTRATIVO DE DEFESA ECONÔMICA (2018). Pesquisa processual. Processo 08700.011091/2015-2018.

CALLON, M. (1998). "Introduction: the embeddedness of economic markets in economics". In: CALLON, M. (org.). The law of markets. Oxford, Blackwell.

CANETTIERI, T. (2017). A produção capitalista do espaço e a gestão empresarial da política urbana: o caso da PBH Ativos S/A. Revista Brasileira de Estudos Urbanos e Regionais, v. 19, n. 3, pp. 513-529.

CASTELLS, M. (1977). The urban question. Londres, Edward Arnold.

CHIAPELLO, E. (2015). Financialisation of Valuation. Hum Studies, n. 38, pp. 13-35.

CHRISTOPHERS, B. (2014a). From Marx to markets and back again: performing the economy. Geoforum, v. 57, pp. $12-20$.

(2014b). Wild dragons in the city. Urban political economy, affordable housing development and the performative world making of economic models. International Journal of Urban and Regional Research, v. 38, n.1. pp. 79-97.

(2015). The limits to financialization. Dialogues in Human Geography, v. 5, n. 2, pp. 183-200.

CNACD - COORDENAÇÃO NACIONAL DA AUDITORIA CIDADÃ DA DÍVIDA (s/d). Projetos cifrados. LS 204/2016, PLP 181/2015 e PL 3337/2015 - visam “legalizar” esquema fraudulento. Brasília, CNACD.

DESROSIÈRES, A. (2002). The politics of large numbers. A history of statistical reasoning. Cambridge, Harvard University Press. 
ENGELS, F. (s/d). “Contribuição ao problema da habitação”. In: MARX, K. e ENGELS, F. Obras Escolhidas. Volume II. São Paulo, Alfa Omega.

FAULHABER, G. R. e BAUMOL, W. J. (1988). Economists as innovators: practical products of theoretical research. Journal of Economic Literature, v. 26, n. 2, pp. 577-600.

FIX, M. (2011). Financeirização e transformações recentes no circuito imobiliário no Brasil. Tese de Doutorado. Campinas, Universidade Estadual de Campinas.

FROUD, J.; SUKHDEV, J. e WILLIAMS, K. (2002). Financialization and the coupon pool. Capital \& Class, v. 78, pp. 119-152.

GOTHAM, K. F. (2009). Creating liquidity out of spatial fixity: the secondary circuit of capital and the subprime mortgage crisis. International Journal of Urban and Regional Research, v. 33, n. 2, pp. 355-371.

GRAHAM, S. e MARVIN, S. (2001). Splintering urbanism. Networked infrastructures, technologiocal mobilities and the urban condition. Londres e Nova York, Routledge.

GRÜN, R. (2007). Decifra-me ou te devoro! As finanças e a sociedade brasileira. Mana, v. 13, n. 2, pp. 381-410.

GUIRONNET, A. e HALBERT, L. (2015). Urban development projects, financial markets, and investors: $A$ research note. Chairville, École des Ponts Paritech.

HAILA, A. (2016). Urban land rent. Singapore as a property state. West Sussex, Wiley Blackwell.

HARVEY, D. (1982). Limits to capital. Oxford, Basil Blackwell e Chicago, University of Chicago Press.

HELLEINER E. (1994). States and the re-emergence of global finance: from Bretton Woods to the 1990 s. Ithaca e Londres, Cornell University Press.

HENRIKSON, L. F. (2009). Are financial markets embedded in economics rather than society? A critical review of the performativity thesis. DIIS Working Paper. Copenhagen, Danish Institute for International Studies.

HILFERDING, R. (1910). Finance capital. Londres, Routledge \& Kegan Paul.

JÄGER, J. (2003). Urban land rent theory: a regulationist perspective. International Journal of Urban and Regional Research, v. 27, n. 2, pp. 233-249.

JESSOP, B. (2000). The crisis of the national spatio-temporal fix and the tendential ecological dominance of globalizing capitalismo. International Journal of Urban and Regional Research, v. 24, n. 2, pp. 323-360.

KLINK, J. (2018). On contested water governance and the making of urban financialization. Exploring the case of metropolitan São Paulo, Brazil. Mimeo. Documento submetido ao periódico.

KLINK, J. e BARCELLOS DE SOUZA, M. (2017). Financeirizacão, conceitos, experiências e a relevância para o campo do planejamento urbano brasileiro. Cadernos Metrópole, v. 19, n. 39, pp. 379-406.

KLINK, J. e DENALDI, R. (2014). On financialization and state spatial fixes in Brazil. A geographical and historical interpretation of the Housing Program My House My Life. Habitat International, v. 44, pp. 220-226.

KLINK, J. e STROHER, L. (2017). The making of urban financialization? An exploration of Brazilian urban partnership operations with building certificates. Land Use Policy, v. 69, pp. 519-528.

KOWARICK, L. (1979). A espoliação urbana. São Paulo, Paz e Terra. 
LAPAVITSAS, C. (2011). Theorizing financialization. Work, employment and society, v. 24, n. 4, pp. 611-626.

(2013). Profiting without producing. How finance exploits all of us. Londres e Nova York, Verso.

LEFEBVRE, H. (2001). O direito à cidade. São Paulo, Centauro.

LEYSHON, A. e THRIFT, N. (2007). The capitalization of almost everything: the future of finance and capitalism. Theory, Culture \& Society, v. 24, n. 7/8, pp. 97-115.

LÓPEZ, I. e RODRíGUEZ, E. (2011). The Spanish model. New Left Review, v. 69, pp. 5-28.

MACKENZIE, D. (2005). An engine, not a camera: how financial models shape markets. Cambridge, MIT Press, MA.

MARICATO, E. (1987). Política habitacional no regime militar. Petrópolis, Vozes.

McCANN, E. (2011). Urban policy mobilities and global circuits of knowledge: Toward a Research Agenda. Annals of the Association of American Geographers, v. 101, n. 1, pp. 107-130.

MOODY's INVESTORS SERVICE (2013). SABESP: Perspectiva estável. Disponível em: http://www. sabesp.com.br/sabesp/filesmng.nsf/15652B2BF431F72083257BAA00719176/\$File/PR_Sabesp_ Port.pdf. Acesso em: 5 maio 2018.

MORRIS, C. R. (2008). The two trillion dollar meltdown. Easy money, high rollers, and the great credit crash. Nova York, PublicAffairs.

MOULAERT, F. (2005). Institucional economics and planning theory: a partnership between ostriches? Planning Theory, v. 4, n. 1, pp. 21-32.

MOURÃO, H. S. (2017). A precificação dos serviços de saneamento de água e esgoto e o objetivo social. São Bernardo do Campo. Dissertação de Mestrado. São Bernardo do Campo, Universidade Federal do $A B C$.

NITZAN, J. e BICHLER, S. (2009). Capital as power. A study of order and creorder. Londres e Nova York, Routledge.

OLIVEIRA, F. de (1972). A economia brasileira: crítica à razão dualista. São Paulo, Novos Estudos. (1998). Os direitos do antivalor. Petrópolis, Vozes.

PECK, J. e WHITESIDE, H. (2016). Financializing detroit. Economic Geography, v. 92, n. 3, pp. 235-268.

PRYKE, M. e ALLEN, J. (2017). Financialising urban water infrastructure: extracting local value, distributing value globally. Urban Studies online first, pp. 1-21.

REZENDE, F. (2010). “Em busca de um novo modelo de financiamento metropolitan”. In: MAGALHÃES, F. (org.). Regiões Metropolitanas no Brasil. Washington, Banco Interamericano de Desenvolvimento, pp. 45-98.

RIBEIRO, L. C. de Q. (1991). Da propriedade fundiária ao capital de incorporação: as formas da produção da moradia na cidade do Rio de Janeiro. Tese de Doutorado. São Paulo, Universidade de São Paulo.

RIBEIRO, L. C. de Q. e DINIZ, N. (2017). Financeirização, mercantilização e reestruturação espaçotemporal: reflexões a partir do enfoque dos ciclos sistêmicos de acumulação e da teoria do duplo movimento. Cadernos Metrópole, v. 19, n. 39, pp. 351-378.

ROOYEN, V. C. e HALL, D. (2007). Public is as private does. The confused case of Rand Water in South Africa. Municipal Services Project. Occasional Paper series, n. 15. Cape Town, Logo Printers. 
ROYER, L (2014). Financeirização da política habitacional: limites e perspectivas. São Paulo, Annablume.

SABESP (2016). Relatório anual. São Paulo, Sabesp.

SANFELICI, D. e HALBERT, L. (2015). Financial markets, developers and the geographies of housing in Brazil: a supply side account. Urban Studies, jun. 19, pp. 1-21.

SHIMBO, L. (2012). Habitação social de mercado. A confluência entre Estado, empresas construtoras e capital financeiro. Belo Horizonte, C/Arte.

SOJA, E. W. (2001). Postmetropolis. Critical studies of cities and regions. MA (USA); Oxford (UK); Melbourne (Australia); Berlin, Blackwell.

SOLANES, M. (2013). The Washington consensus, chilean water monopolization and the peruvian draft water law of the 1990s. Water Alternatives, v. 6, n. 2, pp. 207-217.

SWYNGEDOUW, E. (2013). "Águas revoltas. A economia política dos serviços públicos essenciais". In: HELLER, E. e ESTEBAN CASTRO, J. E. (orgs.). Política pública e gestão de serviços de saneamento. $\mathrm{BH}$, Editora UFMG e Rio de Janeiro, Editora Fio Cruz.

TOPALOV, C. (1974). Les promoteurs immobiliers: contributions à l'analyse de la production capitaliste du lodgement en France. Paris, Mouton.

VILLAÇA, F. (1999). “Uma contribuição para a história do planejamento urbano no Brasil”. In: DEÁK, C. e SCHIFFER, S. R. (orgs.). O processo de urbanização no Brasil. São Paulo, Edusp.

WEBER, R. (2010). Selling city futures: the financialization of urban redevelopment policy. Economic Geography, v. 86, n. 3, pp. 251-74.

ZWAN van der, N. (2014). Making sense of financialization. Socio-Economic Review, v. 12. Disponível em: https://www.researchgate.net/publication/274049273_Making_Sense_of_Financialization. Acesso em: 17 jun 2018.

Texto recebido em 19/jul/2018

Texto aprovado em 16/set/2018 